\title{
DINÂMICAS COMERCIAIS DA CIDADE DE OIAPOQUE - AP - BRASIL: SOB O CONTEXTO FRONTEIRIÇO
}

\author{
Commercials dynamics of the city of Oiapoque - AP - Brazil: \\ under the frontier context
}

\begin{abstract}
Audalice dos Santos Feitosa Estudante de Pós-Graduação no Curso de Especialização em Geografia da UNIFAP / Campus Binacional. Grupo de Estudos Urbanos da Amazônia Setentrional (GEURBAS- CNPq). audalicefeitosa@gmail.com
\end{abstract}

Edenilson Dutra de Moura Docente da Universidade Federal do Amapá (UNIFAP) Campus Binacional - Oiapoque. Doutorando em Geografia pela Universidade Federal do Ceará. Coordenador do Grupo de Estudos Urbanos da Amazônia Setentrional (GEURBAS- CNPq). edenilson.moura@unifap.br

RESUMO: Este artigo tem como objetivo evidenciar as influências das relações da fronteira francobrasileira na economia da cidade de Oiapoque-AP. A fronteira aqui analisada apresenta especificidades que a difere das demais fronteiras do Brasil, em decorrência do processo de transformação espacial ocorrido ao longo dos anos, sobretudo, no espaço urbano de Oiapoque e por ser a única fronteira brasileira com a União Europeia. Atualmente as relações fronteiriças entre Brasil e Guiana Francesa, especificamente, Oiapoque e Saint George, ocasionam impactos consideráveis na economia da cidade. Na produção do espaço urbano local, o contexto fronteiriço e a localização geográfica da cidade permitem uma dinâmica econômica peculiar que se dinamiza frente à realidade fronteiriça, como, a circulação do Euro e de pessoas do país vizinho no comércio local. Destacam-se também, a economia de garimpo, o setor pesqueiro, o funcionalismo público e as atividades comerciais vinculadas ao setor do turismo. Quanto aos procedimentos metodológicos, destacam-se a realização de leituras em diferentes fontes documentais e bibliográfica, além de pesquisas de campo em diferentes segmentos e instituições da cidade envolvidos com o setor comercial. Este estudo mostra a importância do conhecimento e a compreensão dos fatores vinculados à fronteira franco-brasileira que influenciam no setor comercial local, evidenciando como se constituem as relações socioeconômicas nesta fronteira, o que possibilita o dinamismo do espaço urbano, na contemporaneidade.

Palavras-chave: Dinâmicas comerciais; Relações fronteiriças; Oiapoque-AP.

ABSTRACT: This work aims to show how influences of the frontiers of the Franco-Brazilian border in the city of Oiapoque-AP. The frontier here analyzed specialized in differentiating the other frontiers of Brazil, in relation to the process of spatial transformation that occurred over the years, especially in the urban space of Oiapoque. Currently, international relations have entered Brazil and French Guiana, Oiapoque and Saint George, causing considerable impacts on the city's economy. The production of the local urban space, the border context and the geographical location of the city are an economic alternative that translates into reality for the border, such as a circulation of the Euro and people from the neighboring country on the spot. Also noteworthy are a mining economy, the fishing industry, public services and commercial activities linked to the tourism sector. To the serves to clinical studies, proposed for the publication of readings in different documentary sources and bibliographical, besides field investigations in different segments and institutions of the city with the commercial sector. This

REVISTA GEONORTE, V.9, N.33, p.43-65, 2018.

DOI: 10.21170/geonorte.2018.V.9.N.33.43.65

(ISSN 2237 - 1419) 
DINÂMICAS COMERCIAIS DA CIDADE DE OIAPOQUE - AP - BRASIL: SOB O CONTEXTO FRONTEIRIÇO

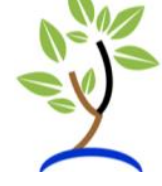

study presents an influence of knowledge and an interface of the components linked to the FrancoBrazilian border that influence the local commercial sector, evidencing as such the socioeconomic conformations in this border, which makes possible the dynamism of the urban space, in the contemporaneity.

Keywords: Commercials dynamics; Frontier relations; Oiapoque-AP.

\section{INTRODUÇÃO}

Este estudo originou-se a partir das reflexões sobre os fatores que alicerçam a dinâmica econômica no espaço fronteiriço franco-brasileiro e como essa dinâmica influência direta e indiretamente na produção do espaço urbano de Oiapoque no período contemporâneo.

É de muita importância que se conheçam os fatores que formatam as engrenagens da dinâmica econômica que nutre o espaço franco-brasileiro e compreender como essa dinâmica influencia diretamente o crescimento do mercado oiapoquense, tornando-se grande agente na composição do espaço urbano de Oiapoque.

Busca-se com essa pesquisa compreender a dinâmica econômica de Oiapoque, bem como as relações socioeconômicas existentes na fronteira franco-amapaense e como essas relações influenciam de várias formas o espaço urbano da cidade de Oiapoque - Amapá - Brasil. Esta compreensão se consiste na identificação na economia de Oiapoque de fatores ligados à questão fronteiriça e que influenciam a economia local. Busca-se ainda, demonstrar os tipos de estabelecimentos comerciais que mais utilizam a moeda Euro no mercado local e pontuar na cidade de Oiapoque, estabelecimentos vinculados à prestação de serviços, como os do setor turístico e relacioná-los com a fronteira internacional Brasil-Guiana Francesa, e mostrar o turismo como possível fator para o desenvolvimento econômico da cidade de Oiapoque.

Espera-se que este trabalho auxilie estudantes, educadores e pesquisadores no entendimento acerca da dinâmica econômica oiapoquense, estimule discussões sobre os impactos das relações diplomáticas (Brasil/França) Oiapoque x Saint George na economia e na transformação espacial urbana de Oiapoque. Ao mesmo tempo, é inegável o ensejo que este trabalho seja arma na afirmação de que a economia gerada nas relações entre as cidades fronteiras (Oiapoque/Saint George) é promotora da produção do espaço urbano de Oiapoque nas suas mais diversas dimensões. 
DINÂMICAS COMERCIAIS DA CIDADE DE

OIAPOQUE - AP - BRASIL: SOB O CONTEXTO

FRONTEIRIÇO

\section{MATERIAIS E MÉTODOS}

\section{Caracterização da Área de Estudo}

A pesquisa foi realizada no espaço urbano do município de Oiapoque, situada as margens do rio homônimo, localizado no extremo norte do estado do Amapá, como mostra o mapa (figura 01) abaixo. Fica a $590 \mathrm{Km}$ de Macapá. Faz limite com o município de Calçoene, Serra do Navio, Pedra Branca do Amapari e Laranjal do Jari, possui as seguintes coordenadas geográficas, Latitude: $3^{\circ} 50^{\prime} 10^{\prime \prime} \mathrm{N}$ e Longitude: $51^{\circ}$ 12' 54" W. O município foi criado em 23 de maio de 1945, e possui uma extensão territorial de $22.625 \mathrm{~km}^{2}$ (IBGE, 2010).

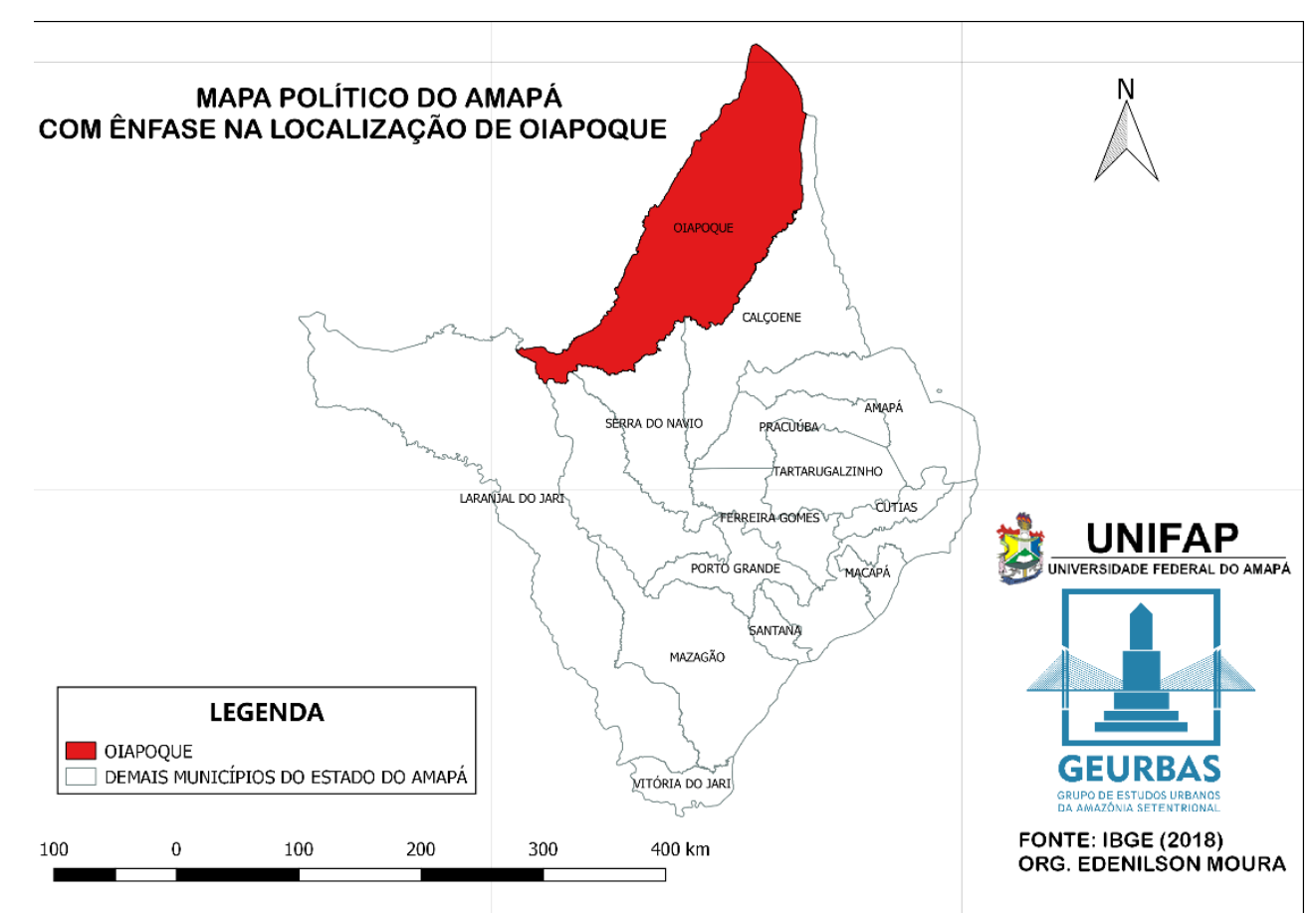

Figura 01: Mapa de localização do Município de Oiapoque e seus limites territoriais. Fonte: COSTA, 2000. Adaptado por MOURA, 2018.

A cidade de Oiapoque atualmente dispõe de dez bairros: Centro, Nova Esperança, Planalto, Paraíso, Russo, Nova União, Fazendinha, FM, Universidade e Infraero. Projeções para outros bairros. Destacando-se o Bairro do Centro com a maior concentração de estabelecimentos comerciais, como mostra a figura 02 a seguir. 


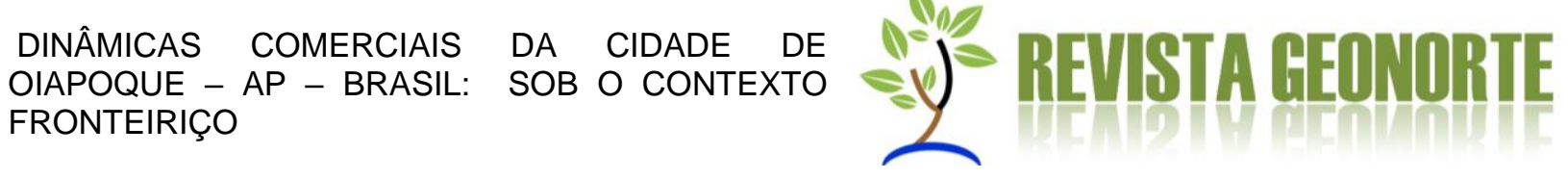

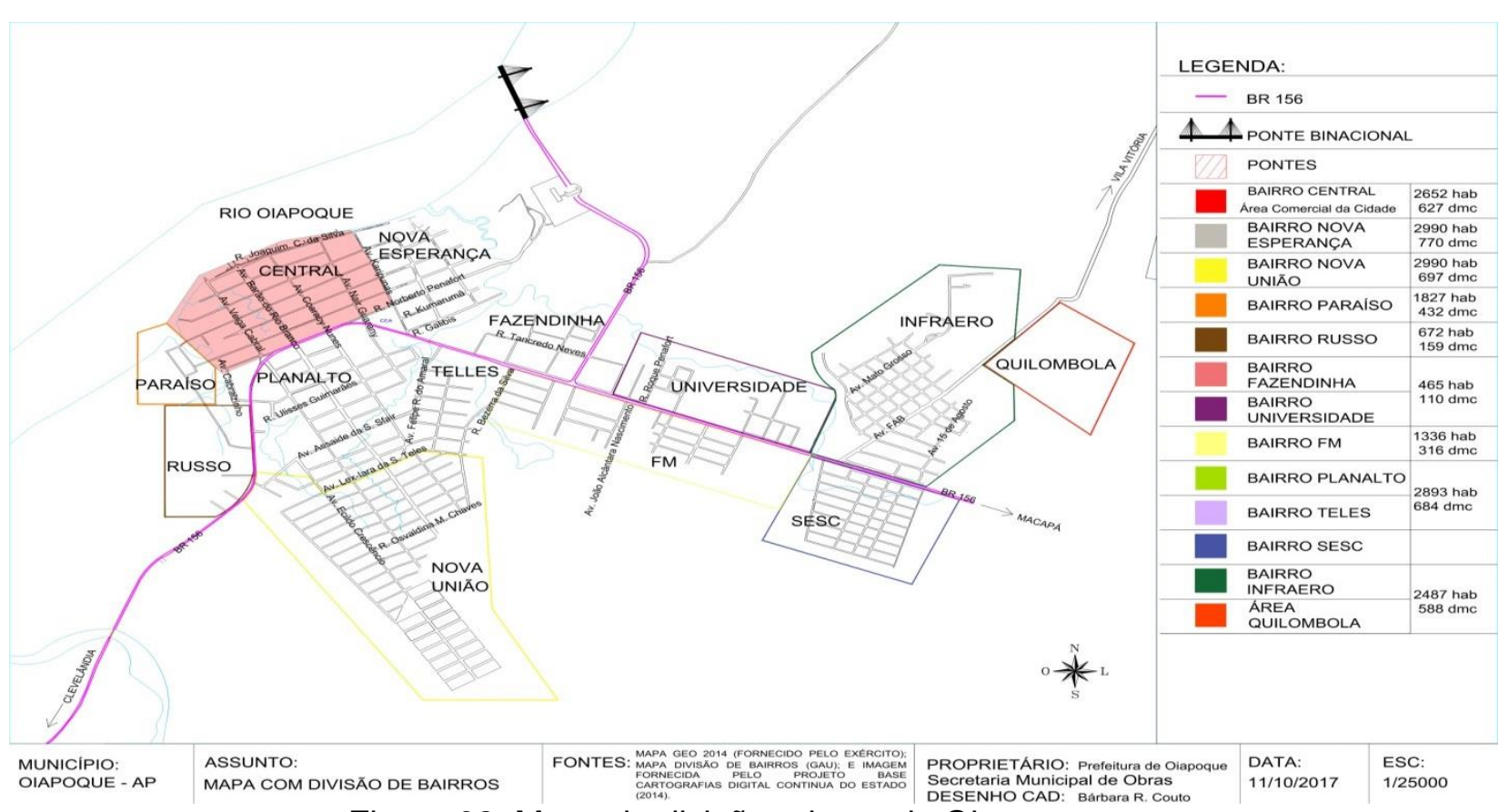

Figura 02: Mapa da divisão urbana de Oiapoque.

Fonte: COUTO, 2017. Adaptado pelos autores, 2018.

Este artigo é fruto de uma pesquisa vinculada ao Grupo de Pesquisa e Estudos Urbanos da Amazônia Setentrional (GEURBAS / CNPq) e integra ações do Projeto de Pesquisa: Do Oiapoque ao... Possível desvelar urbano na fronteira franco-brasileira, registrado na Universidade Federal do Amapá - Campus Binacional de Oiapoque.

Esta análise priorizou, especificamente, o espaço urbano do município de Oiapoque, onde a dinâmica econômica tem elemento tátil, visual, ela é contínua, mas não linear. O estudo foi desenvolvido no período compreendido entre os meses de abril de 2017 a fevereiro de 2018. Sobre os procedimentos iniciais de uma pesquisa, Lakatos e Marconi (2011, p. 253) pontuam que, o trabalho científico do modo geral, inicia-se com a coleta de dados, sejam eles bibliográficos ou de pesquisa de campo, suspostamente importantes para um referido problema.

Portanto, a metodologia utilizada para se alcançar os objetivos da pesquisa foi levantamentos bibliográficos em livros, artigos científicos, teses, monografias, dissertações, bem como, a realização de pesquisa em campo, onde foram entrevistados: a presidenta da Associação Comercial e Oiapoque (ACOI), a diretora local do Sistema Brasileiro de Apoio às Micro e Pequenas Empresas (SEBRAE), o presidente da Cooperativa Mista Fluvial de Catraieiros de Oiapoque (COMFCOI), o presidente da Associação dos Taxistas de Oiapoque e também alguns, proprietários de estabelecimentos comerciais e de estabelecimentos vinculados a atividades turísticas, através de roteiros de entrevistas com perguntas estruturadas e semiestruturadas e entrevistas gravadas, para a coleta de informações e dados sobre a temática, que juntamente com o referencial teórico, estruturou o trabalho. Para este artigo sintetizamos e selecionamos alguns dos principais dados obtidos por meio de levantamentos em campo. 
DINÂMICAS COMERCIAIS DA CIDADE DE OIAPOQUE - AP - BRASIL: SOB O CONTEXTO FRONTEIRIÇO

Também se realizou o registro de fotografias, dos diferentes tipos de estabelecimentos e prestadores de serviços vinculados ao setor turístico. Foi necessário realizar a busca dos materiais importantes para este estudo em sites de internet, o que é parte dificultoso, pois, há uma grande dificuldade ao acesso de internet na cidade.

\section{RESULTADO E DISCUSSÕES}

A pesquisa bibliográfica em conjunto com o trabalho de campo foi importante para identificar os principiais fatores que influenciam na dinâmica econômica e na dinamização do espaço urbano da cidade de Oiapoque.

Durante o andamento deste estudo foram feitas visitas a órgão como o SEBRAE e associações como a ACOI, a proprietários de estabelecimentos comerciais vinculados a atividades turísticas, entre outros, com o intuito de realizar entrevistas com seus representantes, para coleta de dados e informações sobre a economia local e a influência fronteiriça na economia oiapoquense e no dinamismo da produção do espaço urbano.

\section{Economia e Cidade: Geografia (s)}

Ao observar a relação entre economia e a questão urbana, torna-se possível fazer uma análise geográfica das questões socioeconômicas e espaciais relacionadas as dinâmicas comerciais, as quais se apresentam como partes integrantes das dinâmicas do espaço geográfico, principalmente nas cidades. A ciência geográfica, a partir da Geografia Econômica possibilita a compreensão dessa relação.

Geografia Econômica é o ramo da Geografia humana que estuda os fenômenos econômicos distribuídos espacialmente, estuda a organização, a produção e reprodução econômica desse espaço, Costa (2009, p.10). A geografia econômica tem como objetivo estudar as transformações espaciais desencadeadas pelas relações socioeconômicas, a localização e a organização das diversas atividades econômicas. De acordo com Claval (2005, p.13), a Geografia Econômica estuda os circuitos econômicos e de redistribuição, tendo como objetivo compreender as estratégias dos agentes econômicos [...]. Para Chorincas (2001), a Geografia Econômica é, em poucas palavras, a análise da superfície terrestre em todos os aspectos que interessam do ponto de vista econômico. As relações socioeconômicas são responsáveis pelas transformações ocorridas no espaço geográfico, estruturando determinados lugares de acordo com a atividade econômica desenvolvida, modificando o meio, criando novos ambientes, influenciando os fluxos migratórios, entre outros fatores.

Diante desse contexto analisado, podemos entender que o espaço urbano se dinamiza também partir das atividades econômicas desenvolvidas em determinados 
DINÂMICAS COMERCIAIS DA CIDADE DE OIAPOQUE - AP - BRASIL: SOB O CONTEXTO FRONTEIRIÇO

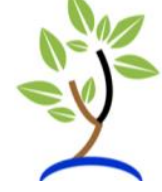

espaços em diferentes épocas, sendo resultado da dinâmica social, no interesse do desenvolvimento.

Já a Geografia Urbana tem como um de seus objetivos desvendar os processos sócioespaciais de produção de nossas cidades em seus nexos econômicos, políticos e simbólicos, Costa (2011, p. 01). Uma vez que a cidade é resultado de atividades humana e sua organização histórica, construídas em diferentes temporalidades. De acordo com Carlos (2013, p. 57) a cidade é uma realização humana, uma criação que vai se construindo ao longo do processo histórico e que ganha materialidade concreta, diferenciada, em função de determinações específicas. Ainda para Carlos (2011, p. 98) na construção da cidade, a natureza adquire a condição de matéria-prima, na qual o trabalho humano é o responsável pelas modificações ocorridas, transformando a natureza em produto humano. Temos então, o uso do espaço sob o capital, antes deste ser submetido a lei do valor, e torna-se, valor de uso e valor de troca, o que torna a cidade (produção histórica), obra e mercadoria no mundo moderno.

Ao se propor realizar um estudo sobre a dinâmica econômica de um determinando espaço, por meio de um acompanhamento voltado para questões sócio-espacial, econômico e cultural, pretende-se analisar e compreender a importância das transformações ocorridas no espaço estudado, desde sua origem até os dias atuais, a partir de informações e dados sobre o objeto de estudo da pesquisa.

Para Santos (1985) a periodização da história é que define como será organizado o território, ou seja, o que será o território e como serão as suas configurações econômicas, políticas e sociais. A partir dessa concepção trataremos sobre as transformações econômicas-espaciais na cidade de Oiapoque, que estão intrinsicamente vinculadas as relações fronteiriças franco-brasileira.

\section{Dinâmicas Comerciais na Cidade de Oiapoque - Amapá}

A base econômica da cidade de Oiapoque, até a primeira metade dos anos de 1990 esteve fundamentada na exploração mineral, especificamente no ouro que era moeda, causa da união de todos os povos, todas as classes sociais dos territórios fronteiros Amapá e Guiana Francesa.

Sobre a exploração do ouro na região de Oiapoque Almeida e Rauber (2017), pontuam que, esta região desde o século XIX, é marcada pela exploração de recursos naturais, sobretudo o garimpo de ouro, que apesar dos dados oficiais desta atividade serem praticamente inexistente, é possível fazer a associação entre crescimento demográfico e expansão da economia dos últimos 30 anos em Oiapoque, nesse período, houve a consolidação da rede de estabelecimentos comerciais e de serviços, principalmente os ligados a economia de garimpo, que contribuíram para fundamentar o crescimento socioeconômico da cidade de Oiapoque. O ouro é a peça razão do povoamento não indígena, na região de Oiapoque. Não fez história sozinho, mas por muito tempo foi o centro da atenção dos diversos setores econômicos, movimentou as relações transfronteiriças, atraiu a migração para Oiapoque, movimentou o mercado local e deu suporte para a urbanização do município.

REVISTA GEONORTE, V.9, N.33, p.43-65, 2018.

DOI: 10.21170/geonorte.2018.V.9.N.33.43.65

(ISSN 2237 - 1419) 
DINÂMICAS COMERCIAIS DA CIDADE DE OIAPOQUE - AP - BRASIL: SOB O CONTEXTO FRONTEIRIÇO

Até o mês de dezembro do ano 2001 a moeda francesa era o Franco, de extensa circulação e detinha forte influência nas relações comerciais entre os povos das duas cidades fronteiras, Oiapoque e Saint George. Competia em igual patamar com o ouro e colocava a moeda brasileira, em posições inferiores do ranking monetário, na fronteira. O Cruzeiro Real era a moeda brasileira que vigorou de $1^{\circ}$ de agosto de 1993 a julho de 1994. Nesse período funcionou como sistema de Unidade Real de Valor URV. Antes desse período o Cruzeiro vivera várias outras fases de mudança no padrão monetário.

Em julho de 1994, quando a República Federativa do Brasil tinha como Presidente Itamar Franco e como Ministro da Fazenda Fernando Henrique Cardoso, o Real entra em circulação e marca a economia brasileira. O Real mudou os rumos econômicos do Brasil, trouxe confiança para o mercado brasileiro e, especialmente na fronteira franco-brasileira, abalou o império do Franco. Oito anos depois, a França adotou o Euro como moeda nacional e o Real brasileiro, perdeu espaço no mercado da fronteira.

O Euro entrou em circulação oficial em janeiro do ano 2002, imediatamente passou a circular, também, na cidade de Oiapoque, dominando o mercado local.

O euro dinamizou a economia da Europa e de outros continentes, atraiu grandes investimentos, dominou o mercado, e promoveu a criação do maior espaço econômico mundial ao redor de uma mesma moeda. Com esse mesmo poderio conquistou os elementos relacionais da política econômica, influenciando na área fronteiriça. $\mathrm{Na}$ primeira metade dos anos 2000, três elementos monetários protagonizavam com o mesmo peso no mercado local de Oiapoque: o Ouro, o Euro e o Real. E os três, cada um na sua importância, dinamizavam o mercado local.

Por força sobretudo de leis ambientais, a partir do ano de 2005, o ouro foi diminuindo sua presença na cena, o Real não encontrou a mesma força que o Euro. A intenção aqui é tratar dos fatores que influenciam a economia de Oiapoque na contemporaneidade. Portanto, é justo falar de um elemento que a partir do instante que chegou a Oiapoque dinamizou as trocas comerciais do município, relacionandose com novas formas de produção do espaço urbano.

O funcionalismo público, o maior responsável pela presença constante da moeda brasileira na cidade, tem parcela de contribuição muito importante na organização da economia e no crescimento urbano em Oiapoque. Em 1943, com a criação do Território Federal do Amapá e a criação do Município de Oiapoque, um número considerável de profissionais federais e estaduais, veio para a cidade, principalmente pelo trabalho nas instituições públicas. O Município também passou a ter seus funcionários e aumentou a circulação da moeda brasileira. O cruzeiro estava no início de uma de suas fases.

Nessa época, apesar do grande tráfego comercial, a dinâmica no mercado local decorria sem precedentes normativos - como regras estabelecidas por estatutos inerentes a área de comércio. Assim, o Município, mesmo vendo o levante de todo o potencial mineral que lhe era fruto, ficava impossibilitado de criar políticas que potencializassem o desenvolvimento sólido do comércio local. Como foi visto, até a década de 1990, a economia local esteve fundamentada na exploração do ouro, era 
DINÂMICAS COMERCIAIS DA CIDADE DE OIAPOQUE - AP - BRASIL: SOB O CONTEXTO FRONTEIRIÇO

uma das mais fortes fontes geradoras da economia de Oiapoque, ainda que outros elementos como a atividade pesqueira, a agricultura, o funcionalismo público, privado, liberal contribuíssem para avolumar a vida financeira da cidade. Contudo, o mercado local não apresentava desenvolvimento sólido, forte, capaz de resistir às infrequências dos fluxos econômicos, embora nunca tenha se esvaziado durante as crises financeiras.

O alto fluxo de migração daquela década fazia a cidade crescer. Este crescimento populacional fixo, passou a exigir a estruturação de serviços como a instalação de instituições públicas, privadas, comerciais e organizações civis. Exigiu também a melhoria da qualidade da oferta dos serviços, a qualidade dos produtos e comércio, ainda que contestável inda hoje. Atendendo parte dessa demanda, foi criada a Associação Comercial de Oiapoque (ACOI) em 13/09/1997, com o objetivo de organizar melhor a classe empresarial e também buscar melhorias para o mercado local e para a sociedade oiapoquense.

Na mesma década, o Governo do Estado do Amapá começa a intervir na política econômica de Oiapoque, injetando esforços políticos na interface das relações comerciais de Oiapoque com vistas a fortalecer os atrativos comerciais locais, estruturar o mercado e assim potencializar o desenvolvimento econômico. Então, a partir da segunda metade da década de 1990, a cidade de Oiapoque entra em um processo intenso de diversificação de suas atividades e modernização de suas instituições e ofertas de serviços. Essa estruturação torna-se fator preponderante na influência direta da dinâmica econômica e do dinamismo da produção urbana. Esta conjuntura viabilizou o ordenamento das atividades e a adoção de novas práticas relacionadas ao fortalecimento econômico da cidade.

Nesse cenário, toda articulação converge cada vez mais para a promoção da solidez nas relações comerciais no espaço fronteiriço, culminando com a fortificação do mercado local oiapoquense. A cidade de Oiapoque hoje apresenta influências vinculadas diretamente às relações fronteiriças que implicam na dinâmica econômica e na produção do espaço urbano, Moura (2018) neste sentido retrata que:

\begin{abstract}
$\mathrm{Na}$ espacialidade fronteiriça, no contexto franco-amapaense, é notório na paisagem urbana a presença de interações que são estabelecidas pela sociedade, onde diferentes práticas econômicas, sociais, políticas e culturais dos diferentes territórios e territorialidades, representados por diferentes protagonistas sociais, como os povos da florestas, indígenas, garimpeiros, ribeirinhos, franco-guianenses, franceses, relacionam-se diretamente e têm no cotidiano urbano, a experiência do viver a/na fronteira, ou seja, a prática das interações sociais das relações internacionais no meio urbano amazônico. (MOURA, 2018, p. 59).
\end{abstract}

Essas influências são notáveis no cotidiano: as pessoas de Saint George e Caiena estão nos estabelecimentos comerciais de Oiapoque, muitos filhos de Oiapoque estudam nas escolas de Saint George, é comum o relacionamento entre oiapoquenses e guianenses, muitos guianenses e franceses possuem propriedades como casas residenciais, hotéis, restaurantes, na cidade de Oiapoque. O interesse

REVISTA GEONORTE, V.9, N.33, p.43-65, 2018.

DOI: 10.21170/geonorte.2018.V.9.N.33.43.65

(ISSN 2237 - 1419) 
DINÂMICAS COMERCIAIS DA CIDADE DE OIAPOQUE - AP - BRASIL: SOB O CONTEXTO FRONTEIRIÇO

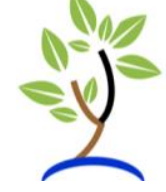

de franceses e guianenses por perfumes, cosméticos e gêneros alimentícios brasileiros é equiparado à intensidade do interesse dos brasileiros pelos mesmos produtos franceses.

É comum pessoas que residem em Oiapoque buscarem atendimento na área da saúde em Saint George, que dispõe de melhores recursos em equipamentos e estruturas, para atender aqueles que buscam atendimento na fronteira vizinha. A cidade de Oiapoque nasceu e cresceu coetâneo a Saint Georges. Essas duas possessões possuem laços fortes no aspecto comercial e cultural. Nas festividades da cidade de Oiapoque, não falta a presença dos vizinhos fronteiriços, sejam festas religiosas, populares, cívicas. Nas festividades da semana da Pátria, são pontuais e assíduos, inclusive desfilam no dia sete de setembro, juntamente com as entidades brasileiras. Além disso, comungam várias crendices, participam das mesmas instituições religiosas.

Daí a facilidade nas boas relações diplomáticas que por sua intensa característica torna-se influente na dinâmica econômica e na produção do espaço urbano de Oiapoque. Ora, para dar sustentabilidade à relação comercial existente entre essas cidades gêmeas - e que é muito importante para Oiapoque, a cidade brasileira sempre adotou na sua política comercial uma forma de atender a demanda, guianense e francesa, por produtos e serviços oriundos de Oiapoque, por exemplo recebendo a moeda "do lado de lá".

Esta proposição ganha reforço teórico nos estudos de Oliveira (2011, p.17) quando, sobre a economia local e questões sociais, afirma que o município de Oiapoque possui uma dinâmica própria, influenciada por certas relações transnacionais tendo uma influência direta na economia e nas questões sociais no extremo norte do Brasil.

A dinamização da produção e organização do espaço urbano de Oiapoque é resultado das atividades humanas, também relacionado com a localização geográfica, sendo influenciado por sua dinâmica econômica e suas relações fronteiriças sobre a produção do espaço urbano. O que se justifica a partir da concepção de Corrêa (2014, p. 43) sobre a produção do espaço urbano, afirmando que, a produção do espaço, seja o da rede urbana, seja intra-urbano, é consequência da ação de agentes sociais concretos, histórico, dotados de interesses, estratégias e práticas espaciais próprias, e desta forma relacionamos e compreendemos a produção do espaço urbano na escala local.

A dinâmica econômica de Oiapoque no seu diversificado universo, promoveu o crescimento e a organização do espaço urbano que, com vistas a recepcionar seu público alvo, passa a interagir com os confluentes naturais desse processo de organização, compatibilizando sua estrutura social e física com os padrões da cultura e se relacionando com o turismo, por exemplo.

Assim, houve crescimento considerável na rede de hotelaria, balneários, a gastronomia local foi dinamizada com novas técnicas e variedade de produtos, os prédios residenciais e comerciais modernizaram suas estruturas físicas, garantindo visual mais contemporâneo à cidade, sobretudo as instituições públicas, que por sua vez, aumentaram seus quadros de funcionários. O setor de obras públicas também cresceu exigindo a atuação de empresas construtoras, e o resultado desse fluxo de 
DINÂMICAS COMERCIAIS DA CIDADE DE
OIAPOQUE - AP - BRASIL: SOB O CONTEXTO
FRONTEIRIÇO

acontecimentos é consequentemente a maturação do comércio local e o crescimento urbano.

\section{Relações Fronteiriças Entre Oiapoque-BR e Saint George de l' Oyapoque- GF}

Até o início dos anos 2000 a população de Oiapoque tinha passe livre em Saint George, assim como os franceses têm acesso à cidade de Oiapoque, podendo transitar, comprar, visitar amigos, fazer turismo. Atualmente para a entrada de brasileiros em território da Guiana Francesa é necessário, além do passaporte, um visto expresso pelo Consulado Francês que fica localizado em Macapá. Para a entrada de estrangeiros (guianenses e franceses) no território brasileiro, deve-se realizar um registro de entrada na Polícia Federal. No entanto, grande parte dos visitantes do território vizinho, não realizam tal registro.

Oiapoque e Saint George construíram ao longo de suas histórias relações fronteiriças que transcendem os limites territoriais estabelecidos nos vários acordos de fronteira assinados entre essas duas fronteiras. O cotidiano destes dois territórios sempre esteve interligado, fato que facilitou as relações comerciais entre estes dois importantes domínios.

Quando aqui se evidencia, propositalmente, a intensidade do bom relacionamento diplomático entre Oiapoque e Saint George, é para registrar o valor desse bom relacionamento para o desenvolvimento social e econômico de Oiapoque. Isto de forma alguma nega a existência de conflitos de fronteira entre tais países. Essas relações diplomáticas, há mais de uma década, vêm sofrendo estremecimento ocasionado pela política protecionista patriótica dos governantes franceses e guianenses, das últimas duas décadas, que tentam fazer com que seus direitos imperem sobre os direitos dos brasileiros fronteiriços.

A Ponte Binacional sobre o Rio Oiapoque foi planejada há três décadas, período em que brasileiros, franceses e guianenses mantinham saudáveis relações em todas as implicações transfronteiriças. A partir de 2005, o admirável relacionamento ganhou porte de rivalidade, ocasionando muitas contendas com prejuízos consideráveis para os povos brasileiros da fronteira.

A construção e a abertura da Ponte Binacional que tinham no bojo de seus objetivos o fortalecimento da relação diplomática, até o momento além de não atingir sua meta, reforçou a contenda do acesso à fronteira do país vizinho. Após a abertura parcial da referida ponte aumentou o fluxo de pessoas e automóveis do país vizinho em Oiapoque. $\mathrm{O}$ que não acontece no espaço fronteiriço francês quem vem restringindo ainda mais a entrada dos brasileiros em seu território.

Apesar do resfriamento nas relações diplomáticas, os vizinhos binacionais mantêm firme as relações comerciais. É pertinente ressaltar que a relação comercial é fator vital para os dois territórios. Então, mesmo descontentes por algumas razões, eles avançam mantendo os laços fronteiriços. É preciso dizer aqui que o mais descontente é o lado brasileiro, pois este é quem carrega as consequências negativas da situação. 
DINÂMICAS COMERCIAIS DA CIDADE DE OIAPOQUE - AP - BRASIL: SOB O CONTEXTO FRONTEIRIÇO

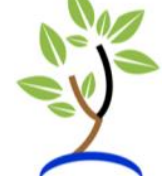

Para Ana Regina Silva (2011, p. 24) as relações fronteiriças são estabelecidas pela sociedade, através das quais se reproduzem práticas econômicas, sociais e culturais entre povos de diferentes esferas territoriais, que, de forma simples compreendem e vivem a realidade das relações internacionais.

É muito importante para os dois territórios a manutenção das relações no ambiente transfronteiriço. Os dois têm consciência plena de tal necessidade e, portanto, procuram administrar suas diferenças com maturidade. Essa postura de maturidade e poder de administração reflete intencionalmente na estrutura e crescimento urbano de Oiapoque. A cidade de Oiapoque, a partir do momento que recebeu um grande fluxo migratório de pessoas, instalações de diversas instituições públicas e privadas, entre outro, expandiu visivelmente ao longo do tempo sua extensão da área urbana.

Apesar de Oiapoque e Saint George conviverem sob o mesmo ideário transfronteiriço e econômico, é flagrante a diferença cultural entre os dois vizinhos: a organização social, a administração pública, a educação escolar, a forma de empreender, a infraestrutura pública dos equipamentos urbanos, o formato arquitetônico, entre outros.

Sobre a organização urbana entre os dois núcleos da fronteira Oiapoque/Saint George, Emmanuel Santos (2012, p. 245), afirma ser perceptível a diferença existente na organização urbana entre esses dois principais núcleos urbanos dessa área de fronteira. Essa diferença se dá pelo fato de Saint George, fazer parte do território de um país desenvolvido: a França, com condições de infraestrutura com melhores condições, uma realidade contrária do município de Oiapoque, localizado em uma região de fronteira periférica de um país com grandes desigualdades sociais.

Na concepção de Silva (2017, p. 11), o comportamento econômico, social, político e cultural de comunas da Guiana Francesa como Camopi, Saint-George-de- L'Oyapock e Cayenne, influencia diretamente na fronteira franco-amapaense, especificamente em Oiapoque, seja na economia ou na paisagem urbana, e isto é muito perceptivo no comércio local e na movimentação de franceses e guiano-franceses transitando no espaço urbano oiapoquense, seja para realizar compras ou como turistas. Como podemos perceber analisando a tabela abaixo. 
DINÂMICAS COMERCIAIS DA CIDADE DE OIAPOQUE - AP - BRASIL: SOB O CONTEXTO FRONTEIRIÇO

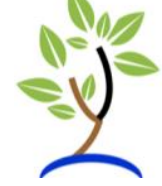

Tabela 01: Dados de entrada de turistas estrangeiros em Oiapoque nos últimos oito anos.

\begin{tabular}{|l|l|l|l|l|l|l|l|l|l|}
\hline $\begin{array}{l}\text { Turistas } \\
\text { Estrangeiros }\end{array}$ & $\begin{array}{l}\text { Ano de } \\
2010\end{array}$ & $\begin{array}{l}\text { Ano de } \\
2011\end{array}$ & $\begin{array}{l}\text { Ano de } \\
2012\end{array}$ & $\begin{array}{l}\text { Ano de } \\
2013\end{array}$ & $\begin{array}{l}\text { Ano de } \\
2014\end{array}$ & $\begin{array}{l}\text { Ano de } \\
2015\end{array}$ & $\begin{array}{l}\text { Ano } \\
2016\end{array}$ & $\begin{array}{l}\text { Ano } \\
2017\end{array}$ \\
\hline $\begin{array}{l}\text { Franceses e } \\
\text { Guianenses }\end{array}$ & 6.905 & 7.176 & 7.312 & 7.533 & 7.734 & 8.212 & 8.434 & 8.727 \\
\hline Haitianos & 2.528 & 2.642 & 2.740 & 2982 & 3.122 & 3.237 & 3.359 & 3.526 \\
\hline Peruanos & 807 & 797 & 815 & 854 & 898 & 882 & 916 \\
\hline $\begin{array}{l}\text { Outras } \\
\text { nacionalidades }\end{array}$ & 3.133 & 3.235 & 3.436 & 3.606 & 3.759 & 4.027 & 4.214 \\
\hline Total & 13.373 & 13.865 & 14.315 & 14.892 & 15.436 & 16.031 & 16.596 & 17.315 \\
\hline
\end{tabular}

Fonte: Polícia Federal - Oiapoque, 2018. Organizado pelos autores. 2018.

A entrada de turistas em Oiapoque aumenta a cada ano, em virtude da distância entre as fronteiras Brasil/França, especificamente, Oiapoque e Saint George, a valorização do euro em relação ao real; o crescimento do mercado local e o grande interesse dos estrangeiros em conhecer e desfrutar da natureza de parte da Amazônia brasileira, no espaço franco-amapaense.

\section{Economia Local na Contemporaneidade}

No século $X X$, especificamente "na primeira década quando ocorreu o boom da exploração do ouro Romani (2010, p.13), na região de Oiapoque, a economia local passa a erguer-se como resultado de atividades relacionadas com o garimpo, como compra e venda de: ouro; materiais apropriados para o trabalho de exploração do ouro; medicamentos contra as doenças comuns na área de garimpo - como malária, leishmaniose, gripe, resfriado, hepatite; gêneros alimentícios; combustível; máquinas indumentária apropriadas para aquele trabalho; bebidas alcoólicas; produto de higiene pessoal. Além do mecanismo compra e venda, estruturaram-se dormitórios, pousadas, hotéis, além de estabelecimentos comerciais como danceterias, bares e lanchonetes.

O intenso fluxo de pessoas que transitavam das cidades de todos os estados brasileiros para Oiapoque, Saint George, Caiena, indo e vindo, gerou a formação de linhas de transporte, principalmente terrestre e fluvial. Até os anos 1990, o transporte de pessoas para Caiena era feito via aérea e fluvial, o que ainda permanece. $O$ transporte fluvial era clandestino, por meio dos coiotes, mas trazia grande

REVISTA GEONORTE, V.9, N.33, p.43-65, 2018.

DOI: 10.21170/geonorte.2018.V.9.N.33.43.65

(ISSN 2237 - 1419) 
DINÂMICAS COMERCIAIS DA CIDADE DE OIAPOQUE - AP - BRASIL: SOB O CONTEXTO FRONTEIRIÇO

movimentação para a economia local. O transporte fluvial até Saint George, iniciou-se feito por canoa a remo ou à vela, depois com canoa de motor de popa. Nesse ponto de evolução do transporte fluvial, já inicia a comercialização do transporte fluvial no trecho Oiapoque Saint George.

$\mathrm{Na}$ contemporaneidade percebe-se na fronteira franco-amapaense, novas dinâmicas econômicas e espaciais, onde a economia do garimpo, já não é tão impactante no setor econômico como em épocas passadas. Essas novas dinâmicas estão relacionadas, sobretudo, com o comércio fronteiriço, a economia da moeda Euro, que é mais valorizada se comparada à moeda brasileira, o Real, com o setor pesqueiro e também o funcionalismo público federal, estadual, municipal. Havendo também as atividades econômicas informal que muito contribui com a economia local, como por exemplo, os vendedores que ocupam os espaços públicos, como as calçadas.

Segundo Rio (2012, p.01), há diversas atividades informais que utilizam os espaços públicos ou dependem deles para a sua existência, essas atividades e práticas econômicas podem ser periódicas. O funcionalismo público nos últimos anos teve que acompanha o curso de toda essa evolução histórica e econômica, que aumenta de forma considerável no município, tanto em nível federal e estadual, quanto municipal ao mesmo tempo que, contribui para o crescimento econômico e espacial da cidade oiapoquense. Ao observar a quantidade de instituições que foram criadas nas últimas duas décadas e outras que aumentaram seus departamentos, é possível dimensionar o crescimento do funcionalismo público em Oiapoque. Entre os anos 1997 e 2017, mais de vinte instituições públicas foram criadas ou instaladas em Oiapoque. Dentre estas estão: Corpo de Bombeiros, IFAP, UNIFAP, Justiça Federal, INSS, Superfácil, Museu Kuahi, E.M.E.F. Leopoldina Amaral, E.M.E.F. Onédia Paes Bentes, Educandário ABC, UBS do Planalto, UBS Nova Esperança, Posto da Polícia Rodoviária Federal, SESC, entre outros.

Além disso, as entidades que já existiam antes desse período, cresceram, aumentaram o número de funcionários. As empresas privadas também cresceram e expandiram seu quadro de funcionários.

O comércio fronteiriço local, figuras 03, apresenta uma grande diversidade de mercadorias, em setores que vão desde os gêneros alimentícios e bebidas, bem como, confecções, calçados, artigos para cama, mesa e banho, eletrodomésticos, móveis, artesanatos, cosméticos, joias, materiais e equipamentos para garimpo, combustível, material de construção. 
DINÂMICAS COMERCIAIS DA CIDADE DE OIAPOQUE - AP - BRASIL: SOB O CONTEXTO FRONTEIRIÇO

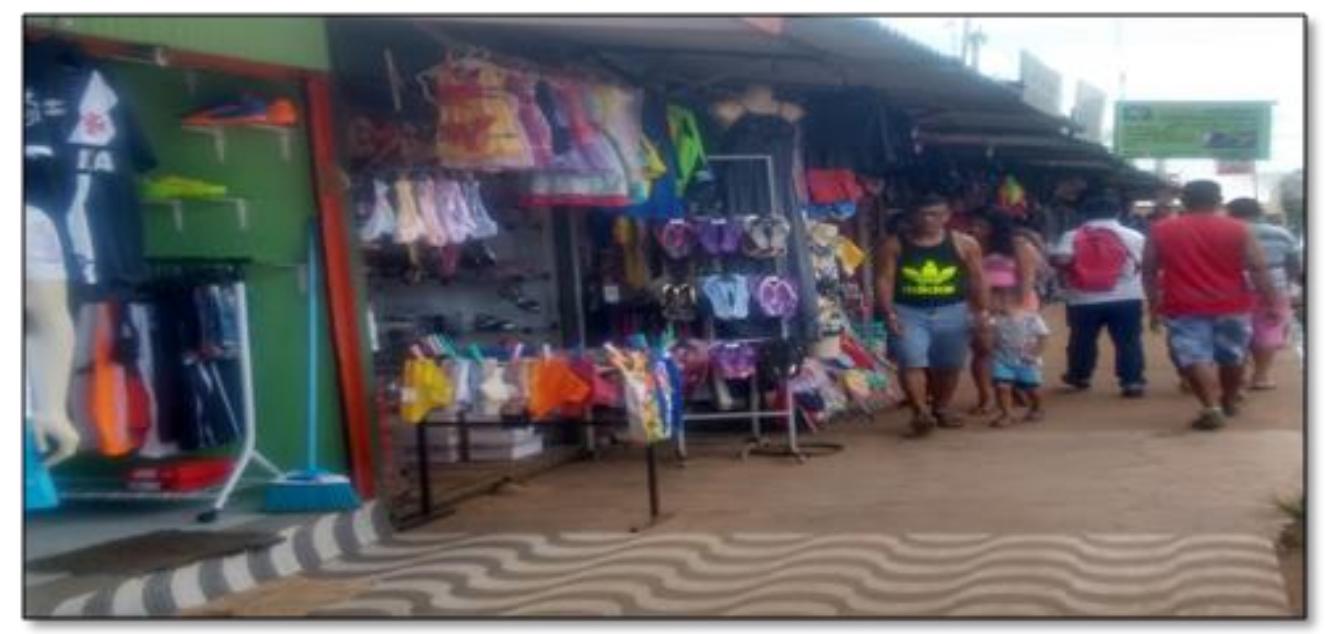

Figura 03: centro de Oiapoque, vendedores ambulantes.

Fotografia: Acervo dos autores 08/2017.

A economia da moeda Euro continua sendo um fator importante no setor comercial local, pois a moeda euro tem valor maior em relação a moeda brasileira o real. A valorização da moeda europeia estimula a troca desta pela moeda brasileira, o que possibilita aos turistas um maior poder de compras. Normalmente essas compras se realizam na cidade de Oiapoque e favorece a economia local.

\section{A Diversidade do Comércio Fronteiriço Oiapoquense}

Em tempos contemporâneos o comércio local continua com forte relação direta e indireta com o ouro e o euro. No caso do ouro, mesmo que tenha diminuído consideravelmente a intensidade de sua presença em vários ângulos das atividades nas relações comerciais, ele não saiu totalmente de cena. Sua atuação ficou bastante reservada, mas, manteve seu grande valor, tanto que há estabelecimentos comerciais que trabalham com venda de material para o garimpo. Esses comércios vendem ferramentas utilizadas nos garimpos como motores elétricos e ferramentas manuais, além de alimentos enlatados e produtos de higiene pessoal, estes comércios aceitam como moeda de pagamento o real e o euro. Os estabelecimentos denominados joalherias e casas de câmbio, compram e comercializam o ouro e o euro. A figura 4, mostra uma dessas casas câmbio da cidade.

Nestes três casos, ocorre um exemplo de relação direta entre comércio, o euro e o ouro. A relação indiretamente se realiza quando, após o câmbio do ouro e do euro em real, o real é utilizado no mercado local nas diversas transações comerciais desenvolvidas na espacialidade urbana de Oiapoque. 
DINÂMICAS COMERCIAIS DA CIDADE DE OIAPOQUE - AP - BRASIL: SOB O CONTEXTO FRONTEIRIÇO

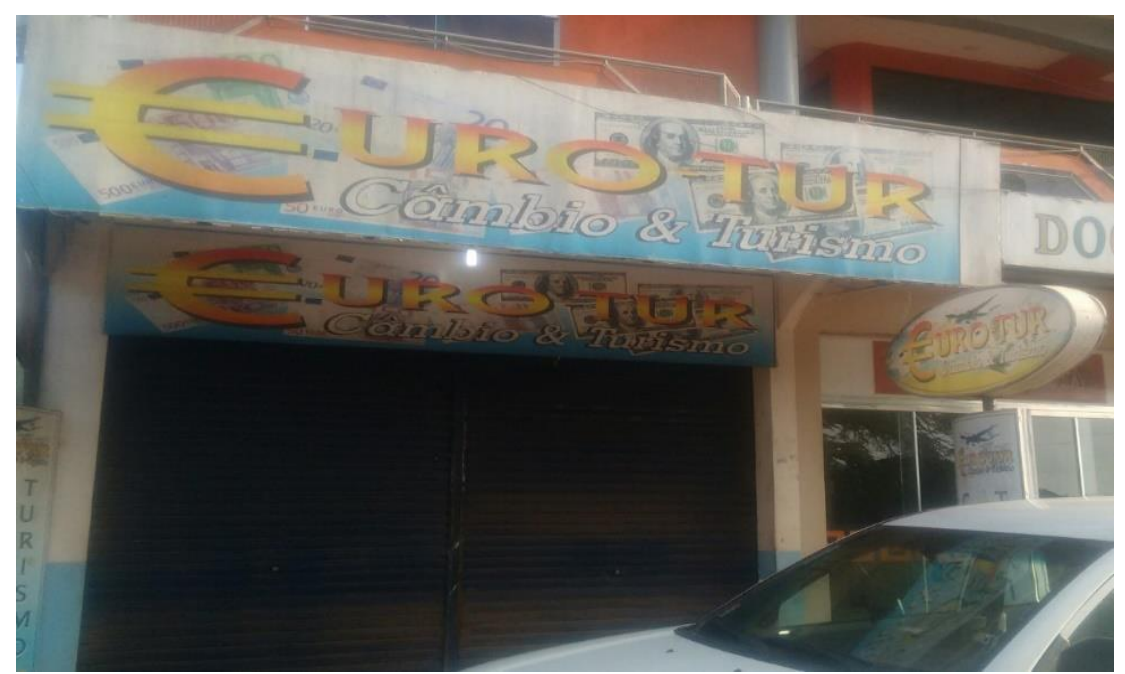

Figura 04: Vista frontal de uma casa de câmbio em Oiapoque. Fotografia: Acervo dos autores, 09/2017.

Essa relação direta e indireta com o ouro e o euro repercute de forma decisiva no aumento dos preços das mercadorias nos estabelecimentos comerciais, o que torna o custo de vida muito alto na cidade de Oiapoque. Para José Silva (2005, p.05), "a circulação do ouro e do euro em Oiapoque é, em grande medida, responsável pela dinâmica do mercado local, inclusive elevando os preços das mercadorias". Outro elemento, muito essencial para o desenvolvimento do comércio e da cidade, mas que também encarece a vida do município é a BR 156 que ainda não está toda asfaltada.

No período inverno amazônico, a BR-156 entre Calçoene e Oiapoque, formam-se atoleiros dificultando o trânsito dos transportes, tanto de passageiro quanto de cargas. Isso faz com que o preço das passagens e das mercadorias aumentem significativamente na cidade. Quando passa a estação do inverno e que chega o verão, os preços permanecem em alta. Sobre a diversidade do comércio local Martins (2008, p. 123) pontua que, "o comércio da cidade de Oiapoque é bastante diversificado", apresentando lojas de confecções, mercantis com produtos diversos para casa, alimentos, frutarias, açougues, lojas de eletrodomésticos e móveis, estabelecimentos que comercializam produtos importados de utilidades do lar, além de comércios que atendem a demanda dos garimpos, como mencionado anteriormente.

\section{A ACOI e a Economia da Cidade de Oiapoque}

Em entrevista realizada com a presidente da Associação Comercial de Oiapoque ACOI, para o levantamento de dados sobre a quantidade de empresario formais devidamente cadastrados na referida associação, nos úlmos sete (07) anos, bem como, levantamento de outras informações sobre a economia local, obtivemos os dados descritos no gráfico na sequência. 
DINÂMICAS COMERCIAIS DA CIDADE DE OIAPOQUE - AP - BRASIL: SOB O CONTEXTO FRONTEIRIÇO

Gráfico 01: Quantidade de empresários regularmente cadastrados na ACOI nos últimos 9 anos.

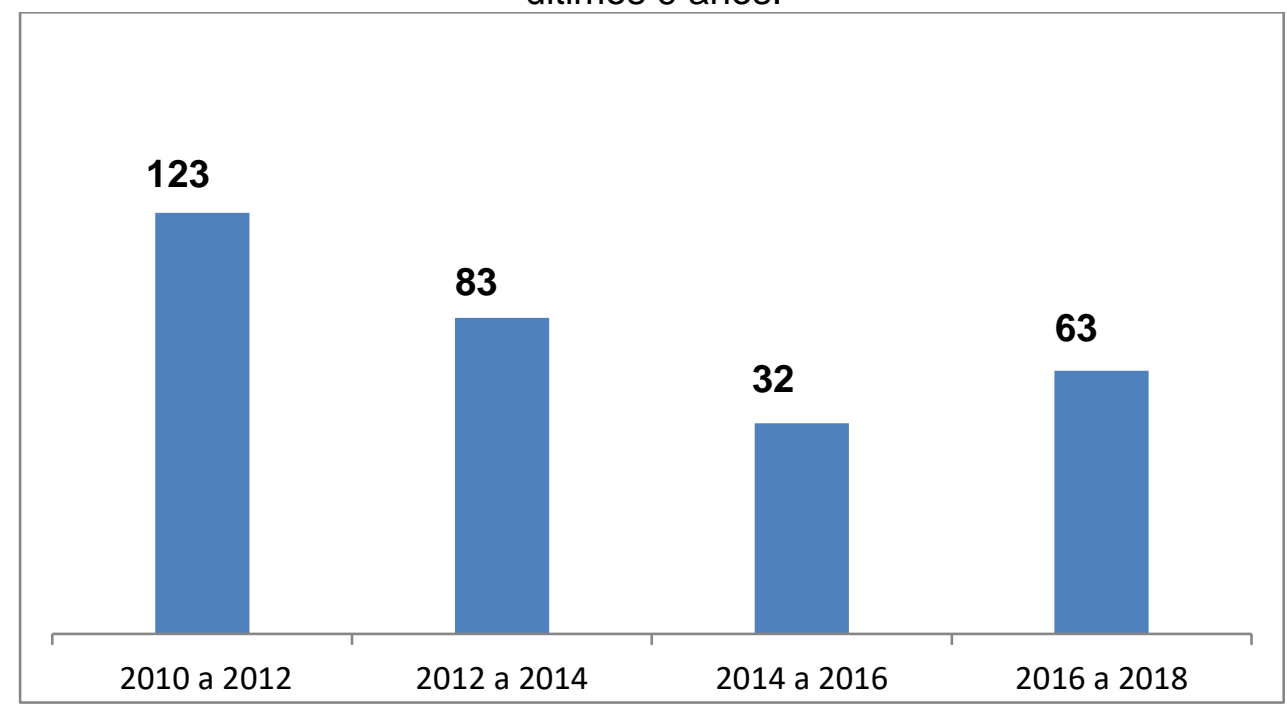

Fonte: ACOI 2017. Organizado pelos autores, 2017.

Percebe-se que a partir do ano de 2012, houve uma redução do número de empresários formais cadastrados na ACOI, diminuindo consideravelmente nos anos de 2014 a 2016. Esse fato ocorreu devido à falta de investimentos público em infraestruturas na cidade, bem como, a alta taxa tributária, o que deixa o empresariado local desestimulado em continuar pagando a taxa correspondente a referida associação que é no valor de $R \$ 40,00$ reais e mais os impostos que são cobrados pelo poder público para o funcionamento de qualquer estabelecimento comercial.

\section{Formalização das Atividades Comerciais: os Microempreendedores na economia urbana}

A partir de 2010, em Oiapoque observa-se (gráfico 02) uma movimentação para a formalização das atividades econômicas local. O Serviço Brasileiro de Apoio às Micro e Pequenas Empresas (SEBRAE), através do Programa de Apoio ao Microempreendedor Individual (MEI), vem incentivando a formalização da classe empresarial local.

Gráfico 02: Quantidade de MEls formalizados em Oiapoque de 2010 a 2017. 
DINÂMICAS COMERCIAIS DA CIDADE DE OIAPOQUE - AP - BRASIL: SOB O CONTEXTO FRONTEIRIÇO

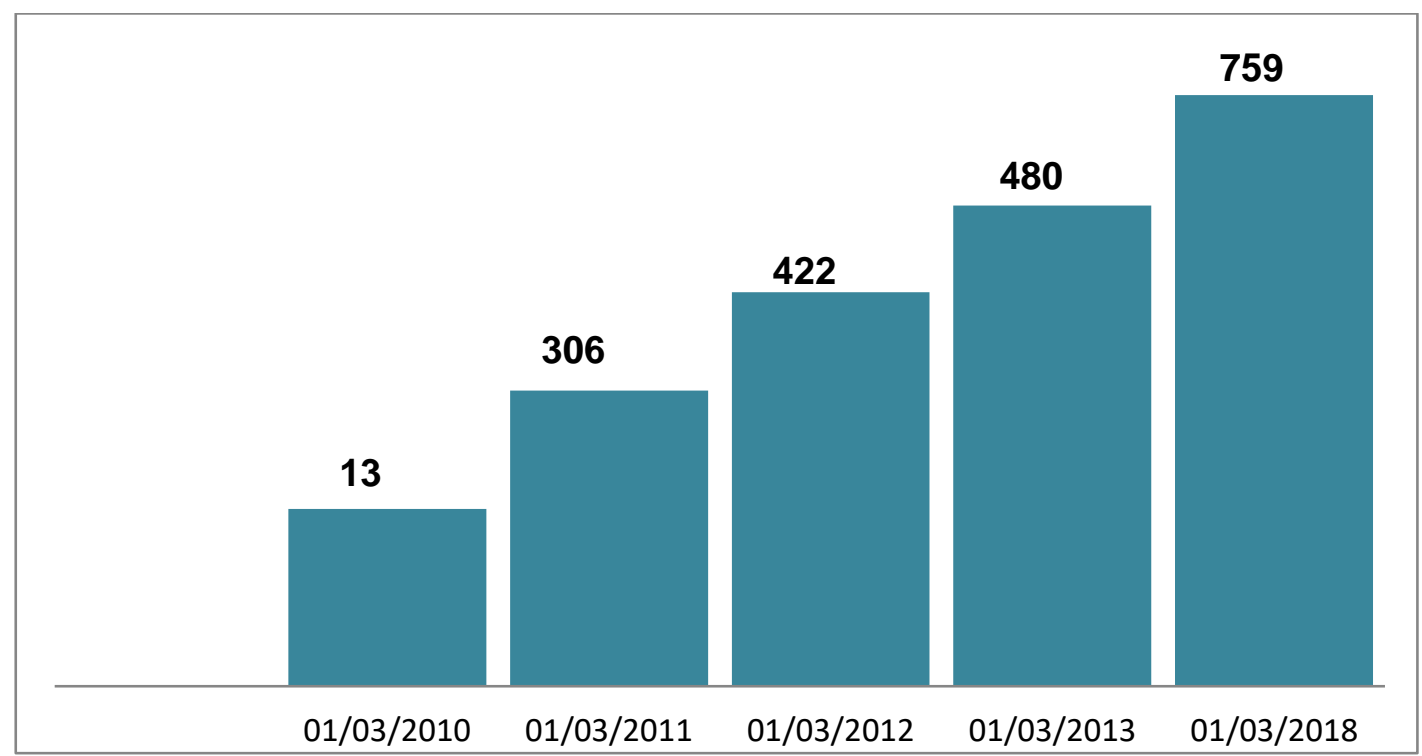

Fonte: Portal do empreendedor 2018. Organizado pelos autores, 2018.

Ao fazermos a análise sobre as atividades econômicas e quantidade de estabelecimentos comerciais de pequeno, médio e grande porte, bem como aos dados sobre a quantidade de MEls formalizados, percebe-se que as atividades e práticas econômicas informais ainda é bastante expressiva na espacialidade urbana de Oiapoque. No período entre 2014 a 2017 não há dados sobre os registros de formalizações de microempreendedores em Oiapoque. As atividades econômicas informais fomentam a economia, mas não contribuem diretamente com a arrecadação tributária municipal. A arrecadação tributária de Oiapoque é relativamente baixa, levando o município a depender de repasses estadual e federal. Como podemos observarmos dados da tabela 02 a seguir.

Tabela 02: Arrecadação e despesas do município nos períodos de 2013, 2015 e 2016 em Reais $(\mathrm{R} \$)$

\begin{tabular}{c|c|c}
\hline Ano & Receita Tributaria & Despesas \\
\hline 2013 & 886,621 & $18,868,077.34$ \\
\hline 2015 & $2,719,117.74$ & $34,699,350.83$ \\
\hline 2016 & $1,630,017.32$ & $27,692,822.07$ \\
\hline
\end{tabular}

Fonte: Prefeitura Municipal de Oiapoque. Organizado pelos autores, 2017.

No mercado local é comum no cotidiano a circulação da moeda euro no pagamento de mercadorias e serviços prestados de todas as naturezas, em qualquer dimensão, quantidade. A supervalorização do Euro em relação a moeda brasileira o Real faz 
DINÂMICAS COMERCIAIS DA CIDADE DE
OIAPOQUE - AP - BRASIL: SOB O CONTEXTO
FRONTEIRIÇO

com que o Euro assuma sempre um lugar de valorização no mercado, sendo essa a preferida em diversos tipos de negociações enquanto o Real fica em segundo plano.

Há uma grande circulação e comercialização desta moeda no espaço urbano de Oiapoque. O que contribui de forma significativa com a economia local. É perceptível na fala dos entrevistados, a ligação do mercado local com a economia da moeda euro. Quando estes afirmam que a economia da cidade de Oiapoque depende de certa forma dos turistas, e que os franceses são os mais cogitados.

Embora a atividade do garimpo de ouro não tenha mais a mesma tônica de antes, ela ainda gera renda para a cidade e permanece no reconhecimento das pessoas de Oiapoque. $\mathrm{Na}$ fala do entrevistado exibida a seguir, um proprietário de estabelecimento comercial, quando perguntado a ele sobre que fatores influenciam a economia local, fica clara a consideração dispensada aos franceses - por causa do euro, e ao garimpo - por causa do ouro.

\begin{abstract}
"O que movimenta o comércio aqui são os franceses, os guianenses, os brasileiros e os índios que moram do lado francês, que quando é época de pagamento lá, eles vem fazer compras e passear aqui na cidade. Eles gastam aqui. E isso movimenta o comércio. Assim também como o pessoal do garimpo, que faz muita compra aqui pra levar pro mato". (M. S. 54 anos, sexo masculino, maranhense, mora em Oiapoque há 17 anos - comerciante local. Pesquisa de campo 09/2017).
\end{abstract}

A moeda europeia, o euro, circula livremente e com alto grau de poder no mercado local, sendo utilizada em diversas transações comerciais, nos diversos estabelecimentos, de grandes, médios e pequenos portes. A valorização desta moeda em relação a moeda brasileira, o real, estimula a concorrência no mercado local e desenvolve a economia deste. A fala de um entrevistado a seguir, um proprietário de restaurante, quando interrogado sobre qual a moeda de maior circulação nas transações comerciais na espacialidade urbana de Oiapoque, registra com clareza a dimensão territorial do uso da moeda euro e o potencial da concorrência gerada em torno dessa moeda com benefícios para o mercado local.

\begin{abstract}
"O euro é a segunda moeda que mas circula aqui dentro da cidade. Todo comércio, restaurante, bar, loja. Todos que trabalham com venda recebe $o$ euro. Tem uns que pagam mas pelo euro que outros. É uma maneira de chamar cliente para o seu estabelecimento".(F. G. 48 anos, sexo masculino, oiapoquense - Proprietário de restaurante. Pesquisa de campo 09/2017).
\end{abstract}

A valorização do euro e sua fácil comercialização permite que um número considerável de turistas venha para Oiapoque, o que gera renda para os diversos estabelecimentos comerciais, em especial para aqueles vinculados a atividades turísticas. Este raciocínio é categoricamente sustentado nas declarações de um comerciante local que contribuiu com esta pesquisa:

"A maior parte dos turistas que vem pra Oiapoque, vem da França. Também vem de outros países. Eu recebo cliente do vários lugar, mas a maioria vem de Cayenne e da França. Esses turistas gostam de vim conhecer o nosso lugar. Isso é bom porque traz renda pra cidade e melhora o movimento no 
DINÂMICAS COMERCIAIS DA CIDADE DE OIAPOQUE - AP - BRASIL: SOB O CONTEXTO FRONTEIRIÇO

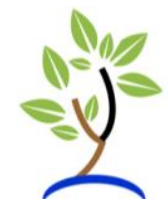

comércio também". (J. V. 58 anos, sexo masculino, natural de Rio Grande do Sul, reside em há 21 anos em Oiapoque - Proprietário de balneário. Pesquisa de campo 09/2017).

\section{O Euro no Comércio Local}

Anteriormente discutiu-se sobre a circulação da moeda euro nas relações comerciais na fronteira franco-brasileira e no mercado local oiapoquense. $O$ euro é realidade cotidiana na vida urbana de Oiapoque. Grande parte dos estabelecimentos comerciais, formais e informais, sejam tradicionais ou marketing de rede, negociam com a moeda euro. Há estabelecimentos que recebem o euro em maior quantidade, com maior dimensão, maior frequência. Há estabelecimentos que, até por conta da natureza de seus produtos, se relacionam com menos intensidade com o euro. Dentre os estabelecimentos comerciais que mais recebem a moeda euro destacam-se os restaurantes, os hotéis, como apresentam as figuras 05,06 na sequência, bem como as pousadas, bares, os comércios de maior porte e estabelecimentos comerciais vinculados a atividades turísticas, como por exemplo, os balneários.

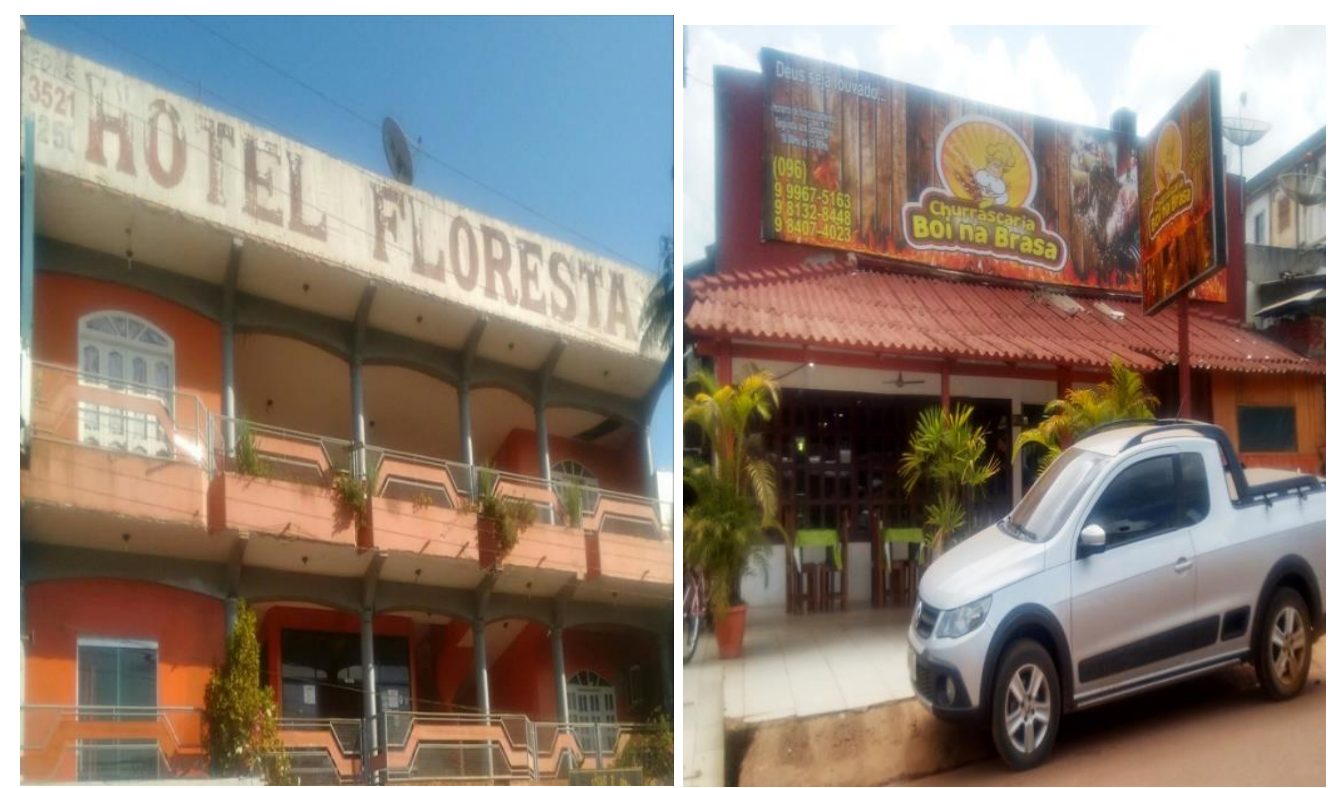

Figura 05: Hotel Floresta e Figura 06: Churrascaria Boi na Brasa, Centro de Oiapoque. Fotografia: Acervo dos autores

\section{O Potencial Turístico de Oiapoque}

O turismo é uma das atividades do setor terciário que mais vem crescendo nos últimos anos, isso tem impulsionado o surgimento de novas opções na área das atividades turísticas, as quais podem ser realizadas em áreas naturais, tais como o turismo rural, o ecoturismo, o turismo de aventura, entre outros, (BRASIL, 2010). 
DINÂMICAS COMERCIAIS DA CIDADE DE OIAPOQUE - AP - BRASIL: SOB O CONTEXTO FRONTEIRIÇO

O turismo no município de Oiapoque ainda é pouco desenvolvido, é mais perceptível no mercado local, no que diz respeito, ao turismo para compras de mercadorias. De acordo com Palhares e Guerra (2016, p. 02) o turismo compõe um conjunto de atividades que contribuem muito para o desenvolvimento econômico local de uma região. Oiapoque dispõe de potencialidades turísticas, como, potencial geológico e geomorfológico, como, rios, cachoeiras, afloramentos rochosos e densa vegetação, favoráveis ao desenvolvimento do turismo natural na região. A implementação e a valorização de mais atividades turísticas no município de Oiapoque poderão contribuir grandemente para desenvolver a economia local, proporcionando melhorias na qualidade de vida aos moradores, bem como, atrair um número maior de turistas para a cidade, dinamizando o espaço geográfico de Oiapoque.

\section{Estabelecimentos Vinculados com a Atividade Turística}

Dentre os diversos tipos de estabelecimentos comerciais na cidade de Oiapoque, existem aqueles vinculados as atividades e prestação de serviços turísticos, como hotéis, chácaras e balneários, como a Chácara Paraíso, Chácara Du Rona, Balneário Km 9, Balneário do KM 7 (figura 07e 08). Algumas chácaras e balneários oferecem além, do lazer turístico, hospedagens e restaurantes, com o intuito de oferecer comodidades aos seus clientes e também como estratégias para atrair clientes, destaca-se que todos estes estabelecimentos recebem a moeda euro.
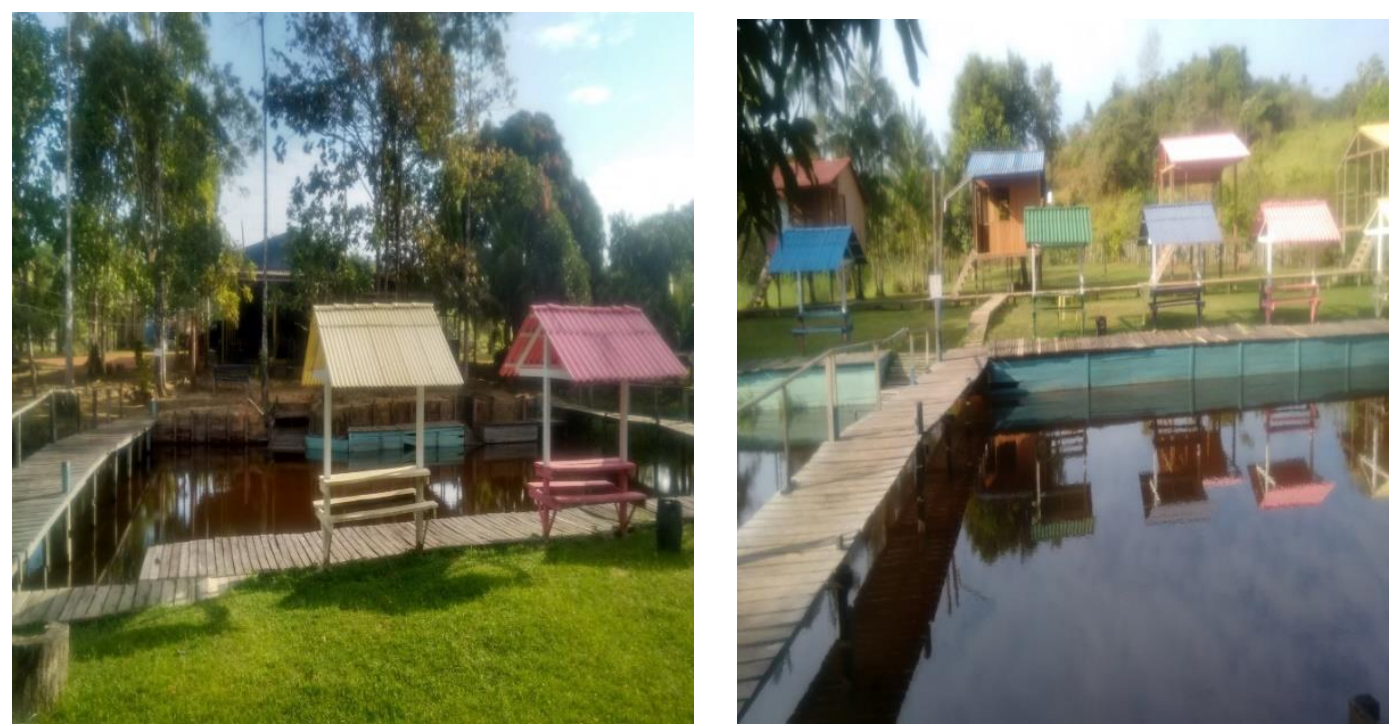

Figura 07 e 08: Balneário do Rio Grande no km 07.

Fotografia: Acervo dos autores, 09/2017. 
DINÂMICAS COMERCIAIS DA CIDADE DE OIAPOQUE - AP - BRASIL: SOB O CONTEXTO FRONTEIRIÇO

A dinâmica espacial contemporânea do município de Oiapoque apresenta novas perspectivas para o desenvolvimento econômico, em especial da espacialidade da cidade, que já não é tão dependente da economia do ciclo do garimpo e da economia do euro, como em épocas passadas tínhamos na economia oiapoquense. A ausência de maiores índices econômicos e também planejamento urbano de Oiapoque está associado à falta de políticas públicas, voltadas para essa área da fronteira francobrasileira, que representa uma importante extensão territorial para o contexto brasileiro, e a sensibilização dos governantes que estão no poder público em realizar mecanismos eficazes para promover uma melhor vida das pessoas que vivem nesta fronteira.

\section{CONCLUSÃO}

Esta pesquisa tratou de questões relacionadas com as dinâmicas comerciais e o dinamismo da produção do espaço urbano da cidade de Oiapoque, bem como, suas relações fronteiriças que influenciam na economia e na produção espacial local. Diante do que foi visto e analisado foi possível constatar que a economia de Oiapoque nos dias atuais já não é tão dependente da economia do garimpo, da economia da moeda europeia, o euro e dos repasses do governo federal e estadual.

Constatou-se que na contemporaneidade surgem novos fatores importantes que contribuem para o desenvolvimento da economia e da espacialidade local, como o setor pesqueiro, o crescimento do funcionalismo público nas três esferas, assim como a expansão de estabelecimentos comerciais vinculadas a atividades turísticas.

Ainda se observam mudanças significativas no comércio na espacialidade urbana de Oiapoque, como: aumento de estabelecimentos comerciais; reestruturação física de vários estabelecimentos comerciais e estabelecimentos vinculados a atividades turísticas; maior e melhor disponibilidade de produtos; e melhorias nos atendimentos ao cliente. As entrevistas realizadas junto as associações e órgãos que estão relacionados com as atividades econômicas, assim como com os empresários que compõe o diversificado mercado local, foram de fundamental importância para se compreender as dinâmicas comerciais na espacialidade urbana de Oiapoque.

Ressalta-se que também são necessárias melhorias em infraestruturas, como: saneamento básico, melhorias de setor energético, asfaltamento da BR-156 entre outros, que são de fundamental importância para o desenvolvimento econômico e espacial da cidade de Oiapoque. E que é importante que se pense em melhorias não somente para fortalecimento e crescimento econômico da classe empresarial de Oiapoque, mas sim melhorias em todos os âmbitos sociais e crescimento econômico que alcance toda a população em maiores nuances. 
DINÂMICAS COMERCIAIS DA CIDADE DE

OIAPOQUE - AP - BRASIL: SOB O CONTEXTO

FRONTEIRIÇO

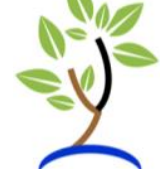

\section{REFERÊNCIAS}

ALMEIDA, C. S.; RAUBER, A. L. Oiapoque, aqui começa o Brasil: a fronteira em construção e os desafios do desenvolvimento regional. REDES: Revista do Desenvolvimento Regional, ISSN-e 1982-6745, Vol. 22, №. 1, 2017, págs. 474-493 2017.

BRASIL. Ministério do turismo. Turismo cultural: orientações básicas. Ministério do Turismo, Secretaria Nacional de Políticas de Turismo, Departamento de estruturação, Articulação e Ordenamento Turístico, Coordenação-Geral de Segmentação. -3. ed. Brasília. Ministério do Turismo, 2010. 96p.

CARLOS, A. F. A. A cidade. 9.ed., 1a reimpressão. - São Paulo: Contexto, 2013. (Repensando a Geografia).

CARLOS, A. F. A. A condição espacial. - São Paulo: Contexto, 2011.

CLAVAL, P. Geografia econômica e economia. 2005.

CHORINCAS, J. Geografia econômica: encontro e desencontro de uma ciência de encruzilhada. 2001. Infogeo, 16/17. Lisboa, Edição Colibri, 2001/2002.

CORRÊA, R. L. Sobre agentes sociais, escalas e produção do espaço: um texto para discussão In: CARLOS, A. F. A. SOUZA, M. L. SPÓSITO, M. E. B. (org.). A produção do espaço urbano: agentes, processos, escalas e desafios - 1.ed. $3^{\underline{a}}$ reimpressão. São Paulo: Contexto, 2014.

COSTA, E. B. Geografia urbana aplicada: possibilidades, utopias e metodologia. XII SIMPURB - Simpósio Brasileiro De Geografia Urbana, Belo Horizonte, 2011.

COSTA, J. E. Geografia econômica. 2009. Universidade Federal de Sergipe, São Cristóvão, CESAD, 2009.

COUTO, B. R. Mapa divisão de bairros da cidade de Oiapoque (GAU): e imagem fornecida pelo projeto base cartografias digital continua do estado do Amapá. 2017

LAKATOS, E. M. Metodologia científica. 6. Ed. - São Paulo: Atlas, 2011.

MARTINS, C. C. Relações bilaterais Brasil/França: A nova perspectiva brasileira para a fronteira Amapá/Guiana Francesa no contexto global. 2008.124 f. Dissertação (Mestrado em Ciências Sociais) - Universidade de Brasília, Brasília- DF, 2008.

MOURA, E. D. Urbano-fronteiriço: espacialidades e especificidades urbanas na fronteira franco-brasileira - Oiapoque - Amapá. In: Revista Casa de Makunaima.
Edição
(2018)
p.
51
65
Disponível 
DINÂMICAS COMERCIAIS DA CIDADE DE OIAPOQUE - AP - BRASIL: SOB O CONTEXTO FRONTEIRIÇO

em:https://casademakunaima.uerr.edu.br/index.php/home/article/view/24/6. Acesso em: 20 de agosto de 2018.

OLIVEIRA, B. S. Dinâmicas sociais na fronteira entre o estado do Amapá e a Guiana Francesa: um estudo sobre Oiapoque, Vila Vitória do Oiapoque e Cayenne. 2011. 126 f. Dissertação (Mestrado em Desenvolvimento Regional) - Universidade Federal do Amapá, Macapá-AP, 2011.

PALHARES, J. M.; GUERRA, A. J. T. Potencialidades no município Oiapoque, Amapá, para o desenvolvimento do geoturismo. Revista Espaço Aberto, PPGG-UFRJ, V.6, N.2, p. 51-72. 2016.

PIRES DO RIO, G. A. A espacialidade da economia: superfícies, fluxos e redes. In: CASTRO, I. E.; GOMES, P. C. C.; CORRÊA, R. L (orgs). Olhares geográficos: modos de ver e viver o espaço. Rio de Janeiro: Bertrand Brasil, 2012.

ROMANI, C. A história entre o oficial e o lendário: interações culturais no Oiapoque. Antíteses, vol. 3, n. 5, jan.-jun. de 2010, , pp. 145-169

SANTOS, E. R. C. Amazônia setentrional amapaense: do "mundo" das águas às florestas protegidas. 2012. 276 f. Tese (Doutorado em Geografia) - Universidade Estadual Paulista, Faculdade de Ciência e Tecnologia, Presidente Prudente- SP, 2012.

SANTOS, M. Espaço e método. São Paulo: Nobel,1985.

SILVA, A. R. F. Perspectivas das políticas territoriais na faixa de fronteira internacional da Amazônia oriental brasileira: estado do Pará e do Amapá. 2011. 190 f. Dissertação (Mestrado em Geografia) - Universidade Federal do Pará, Centro de Filosofia e Ciências Humanas, Belém, 2011.

SILVA, G. V. Desenvolvimento econômico em cidades da fronteira amazônica: ações, escalas, e recursos para Oiapoque-AP. Revista franco-brasileira e geografia. 2017.

SILVA, J. M. A Cidade de Oiapoque e as relações transnacional na fronteira Amapá Guiana Francesa. História Revista. v. 10, n. 2. P. 273-298, jul-dez, 2005. 